\title{
Leading Health Challenges Pine Ridge Reservation, South Dakota Oglala Lakota Sioux
}

\author{
*Kenneth Wienski \\ International Committee of the Red Cross, Walden University, USA
}

Submission: April 28, 2017; Published: May 10, 2017

*Corresponding author: Kenneth Wienski, International Committee of the Red Cross, ICRC, Walden University, Minnesota, USA, Email: Kwienski@aol.com

Abbreviations: AI: American Indians; HIS: Indian Health Services; YPLL: Years of potential life lost; SDDH: South Dakota Department of Health

\section{Leading Health Challenges}

Intergenerational and Historical Trauma has long affected American Indians (AI) down to the genetic level since recent studies have demonstrated genes "...can carry memories of trauma experienced by our ancestors and can influence how we react to trauma and stress [1]. According to the Indian Health Services (IHS) [2], the American Indian (AI) people have long experienced lower health status when compared with other Americans. Lower life expectancy and the disproportionate disease burden exist perhaps because of inadequate education, disproportionate poverty, discrimination in the delivery of health services, and cultural differences. These are broad quality of life issues rooted in economic adversity and poor social conditions (IHS) [2].

Lakota Indians die at higher rates than other Americans from alcoholism (552\% higher), diabetes (800\% higher) all AI (182\% higher), infant mortality (300\% higher), unintentional injuries (138\% higher), homicide $(83 \%$ higher), suicide $(74 \%$ higher) teenage suicide rate is $(150 \%$ higher), cervical cancer (500\% higher), and tuberculosis (800\% higher) (IHS) [2]. The Lakota have the lowest life expectancy of any group in America. Motorists on the Reservation are four times more likely to die in fatal car accidents than anywhere else due to poor roads and alcohol use are major factors (IHS) [2]. As stated by Stacie White, Stanford University: "I traveled to Haiti a month after the 2010 earthquake to report on what was happening there for Stanford Medicine magazine. So when I went to the Rosebud Indian Reservation in South Dakota this year with a group of Stanford students, I was incredulous to learn that the average life expectancy in this community was one year lower than Haiti's - 46 versus 47 - and a full 33 years shorter than the average American, White [3]."

\section{Suicide in NAI}

The trauma that Lakota NAI suffered from the taking away of their land, the removal of their children from their homes and placing them in boarding schools, and the undermining of their NAI culture, have had a profound historical effect on NAI. NAI experience mental issues associated from family problems such as high levels of divorce, physical abuse, drug abuse and domestic violence. The children of these families suffer severe trauma and psychological problems that are manifested in anxiety, depression, attention deficit disorders, and social interactions American Association of Suicidology [4]. Consequently, suicide rates in Lakota NAI are considerably higher than suicide rates in the U.S. American Association of Suicidology [4]. The rate of suicide increases with age and is high among the NAI elderly population because they are more likely to suffer from physical illness or being widowed Stone \& Boldt [5].

According to the County Health Rankings [6], the years of potential life lost (YPLL) before age 75 per 100,000 population (age-adjusted), Shannon County ranks the highest in all counties in South Dakota at 23,851 (YPLL), z-score of 2.94, 293 deaths. The South Dakota Department of Health (SDDH) [7] starting digging deeper into death certificate data to understand why American Indians were dying at younger ages compared to whites. The SDDH identified the leading causes of premature death and that American Indians, in particular South Dakota, have the highest rates of premature mortality in the nation. The SDDH found that AI injury caused mortality; age specific mortality rates compared to whites were highest from 30-39 years of age with a rate ratio of $5.9 \%$. Heart disease caused mortality, age specific rates were highest compared to whites at ages $30-39$ at 4.0 rate ratio. The mortality distribution by age and race for $2004-2009$, was $70 \%$ 
of all AI deaths below 70 years of age compared to $75 \%$ of all white deaths are above 70 years of age. The leading causes of AI death in South Dakota from 2000-2010 were heart disease, unintentional injury, cancer, diabetes, liver disease, suicide, respiratory disease, stroke, influenza/pneumonia, and homicide Christensen [8].

\section{Preventable Risk Factors}

There are preventable risk factors behind the leading causes of premature death for these AI in South Dakota Pine Ridge Reservation. Smoking, obesity, and binge drinking are the leading preventable risk factors of early death. These risk factors increase both chronic causes and injury causes of death because they increase the environments of poverty, unemployment, crime, and insecurity. Additionally, the children grow up, live, and learn with these environments, which are in 3 turn shaped by a wider set of forces: economics, social policies, history, and politics. When evaluating the Social Ecological Model Factors that shape individuals and behavior; Public Policy, Community (cultural values, norms), Organizational (environment), Interpersonal (social network), and Individual (knowledge, attitude, and skills), it has been proven that influencing the Individual Behavior risk factors has shown the most success for this group. Implemented programs that have been helpful to decrease the risk factors include educating the individual of risks of smoking, obesity (increasing fruit and vegetable consumption, increasing regular physical activity), and binge drinking Christensen [8].

\section{Challenges and Barriers}

Clearly there are challenges and barriers to conducting a community health assessment and seeking interventions. It is most important to establish cultural competency among health care workers which involves having the skills required to provide effective clinical and educational care to patients from this particular community. Although Native American Indians may seem invisible to many, they are clearly victims of health disparities [9-11]. Specifically AIs suffer health inequities because of their traditional value system which is incongruent with Western medicine. Additionally, there are language barriers, generational exploitation and geographical barriers are also considerations within this county's population [12-14].
Furthermore, health status is not just a health care issue. It is about ensuring that there are educational opportunities safe communities; adequate housing; and adequate economic and employment opportunities. These things and more, all work in concert to affect health status [15-17]. It is therefore vital that all available resources, federal and private sector, be brought to the light on Indian health issues.

\section{References}

1. Pember Mary Annette (2016) Intergenerational Trauma: Understanding Natives' Inherited Pain. Indian country, Today Media Network, Verona, New York, USA.

2. Indian Health Services (2013) Disparities. US Department of Health and Human service, USA.

3. White Tracie (2013) Broken promises: The state of health care on Native American reservations. Stanford Medicine, USA.

4. American Association of Suicidology (2010) Suicide among American indian/Alaska natives. suicide fact sheet, Span, USA.

5. Stone L, Boldt D (2006) Closing the health disparity gap in new mexico: a roadmap for grant making. New Mexico, USA.

6. County Health Rankings (2013) South Dakota. Robert Wood Johnson Foundation. Wisconsin University, USA.

7. South Dakota Department of Health (2012) Office of family and community health services (public health alliance sites included).

8. Christensen M (2012) Early mortality among American Indians in South Dakota 2000-2010. South Dakota Department of Health. Northern Plains Tribal Epidemologic Center, USA.

9. Backpacks for Pine Ridge (2013) Stats about pine ridge, USA.

10. Blackbear J (2013) Personal Interview.

11. Indian Health Services (nda) Aberdeen area service units and facilities, US Department of Health and Human services, USA.

12. Indian Health Services (2012)Health promotion/Disease Prevention. Community health assessment, USA.

13. Indian Health Services (ndb) (2012) Pine Ridge service units.

14. Indian Health Services (ndc) (2012) Statistics.

15. Pine Ridge Sioux (2013) Pine ridge today.

16. South Dakota Department of Tribal Relations (2013) Pine ridge Indian reservation: Population and housing.

17. United States Census Bureau (2013) Shannon county, South Dakota: Quickfacts.

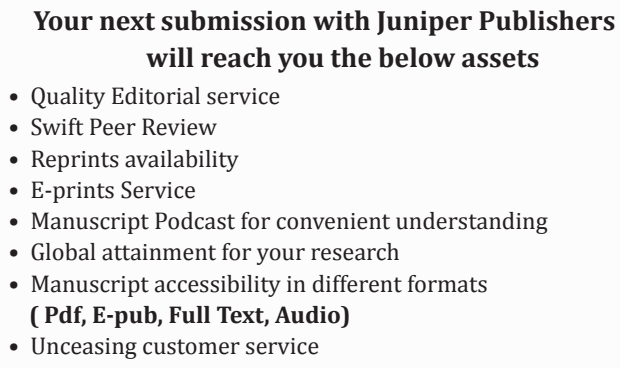

Track the below URL for one-step submission https://juniperpublishers.com/online-submission.php 